\title{
ENSINO ORIENTADO PARA A APRENDIZAGEM BASEADA NA RESOLUÇÃO DE PROBLEMAS E ENSINO TRADICIONAL: UM ESTUDO CENTRADO EM "TRANSFORMAÇÃO DE MATÉRIA E DE ENERGIA"
}

\author{
Sofia Morgado* \\ Laurinda Leite** \\ Luís Dourado*** \\ Célia Fernandes $* * * *$ \\ Eleutério Silva****
}

RESUMO: O Ensino Orientado para a Aprendizagem Baseada em Problemas é uma metodologia de ensino centrada nos alunos que lhes permite aprender conhecimentos novos resolvendo problemas. O objetivo deste estudo foi comparar os contributos desse tipo de ensino, organizado segundo uma abordagem transdisciplinar, com os do ensino tradicional no que concerne à aprendizagem de conhecimentos conceituais, com diferentes níveis de complexidade, no âmbito do tema "Transformação de Matéria e de Energia". Os resultados demonstram que os alunos da turma experimental obtiveram melhor desempenho (apresentaram respostas menos incompletas) do que os alunos da turma de controle nas questões que eram cognitivamente mais exigentes. Apesar de esse tipo de resultados ser esperado, são necessárias mais investigações que permitam testar a sua consistência.

Palavras-chave: Aprendizagem Baseada na Resolução de Problemas. Ciências físicas e naturais. Ensino transdisciplinar.

ENSEÑANZA ORIENTADA PARA EL APRENDIZAJE BASADO EN SOLUCIÓN DE PROBLEMAS Y ENSEÑANZA TRADICIONAL: UNA INVESTIGACIÓN CENTRADA EN “TRANSFORMACIÓN DE MATERIA Y ENERGÍA”

RESUMEN: La Enseñanza Orientada para el Aprendizaje Basado en Solución de Problemas es una metodología de enseñanza centrada en los alumnos que les permite aprender conocimientos nuevos solucionando problemas. El objetivo de esta investigación fue comparar las contribuciones de este tipo de enseñanza, organizada segundo un abordaje interdisciplinario, con los de la enseñanza tradicional con el foco en el aprendizaje de conocimientos conceptuales, con diferentes tipos de complejidad, en el ámbito del tema "Transformación de Materia e de Energía". Los resultados sugieren que los alumnos de la clase experimental tuvieron mejor desempeño (presentaron respuestas menos incompletas) que los alumnos de la clase control en las cuestiones que eran cognitivamente

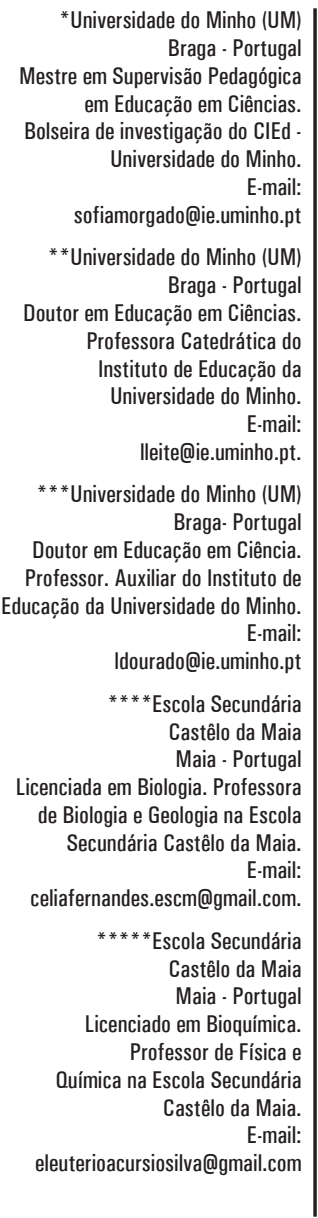

*Universidade do Minho (UM) Servisão Pedagógic em Ciências. Iigação do CIEd E-mail: sofiamorgado@ie.uminho.pt Braga - Portuga Educação em Ciências. Instituto de Educacão da Universidade do Minho. E-mail: de do Minho (UM) Braga- Portugal Doutor em Educação em Ciência. Professor. Auxiliar do Instituto de Educação da Universidade do Minho. Idourado@ie.uminho.pt Castêlo da Maia Portugal Licenciada em Biologia. Professor Biologia e Geologia na Escola E-mail: celiafernandes.escm@gmail.com. Maia - Portugal ciado em Bioquímica. Castêlo da Maia. E-mail: eleuterioacursiosilva@gmail.com 
más exigentes. Aunque este tipo de resultados sea esperado, son necesarias más investigaciones que permitan testar su consistencia.

Palabras clave: Aprendizaje basada en la solución de problemas. Ciencias físicas y naturales. Enseñanza tras-disciplinaria.

PROBLEM-BASED LEARNING AND TRADITIONAL TEACHING: A STUDY FOCUSED ON “MATTER AND ENERGY TRANSFORMATION"

ABSTRACT: Teaching for Problem-Based Learning is a teaching approach centred in students that enables learning new information by solving problems. This paper aims at comparing the contribution of Teaching for Problem-Based Learning according to a transdisciplinary approach, compared to a traditional teaching approach in what concerns students' learning on the theme 'Matter and Energy Transformations'. Data collected through a science knowledge test suggest that the experimental group performed better (presented less incomplete answers) than the control group did regarding high demanding cognitive questions. Even though this type of results was expected, follow up studies are needed in order to test the consistency of the result obtained.

Keywords: Teaching for Problem-Based Learning. Physical and Natural Sciences. Transdisciplinary Teaching. 


\section{CONTEXTUALIZAC̣ÃO}

O atual ritmo de progresso científico e tecnológico requer que os cidadãos possuam um leque diversificado de conhecimentos e competências que lhes permitam aprender ao longo da vida (BYBEE, 2010). Contudo, os alunos portugueses não têm obtido bons resultados nos testes PISA (OCDE, 2014), o que sugere que não estão alcançando a formação desejada. Além disso, diversos estudos têm mostrado que os alunos evidenciam pouco interesse em estudar ciências (SJØBERG; SCHREINER, 2010), que este diminui durante o percurso escolar (KENNEDY; LYONS; QUINN, 2014; POTVIN; HASNI, 2014) e, ainda, que muitos deles não pretendem seguir carreiras profissionais no domínio das ciências e da tecnologia (SJØBERG; SCHREINER, 2010). Estes dados sugerem que é necessário repensar o ensino das ciências que tem sido implementado nas escolas. Segundo alguns autores (HODSON, 2008; HOOLBROK; RANNIKMAE, 2009; EUROPEAN COMISSION, 2015), é necessário que os professores adotem novas abordagens metodológicas que tornem os assuntos do âmbito das ciências compreensíveis para os alunos e que evidenciem a relevância das ciências e da sua aprendizagem para o dia a dia dos cidadãos. Uma das condições a que devem obedecer essas metodologias é a de permitir que o aluno passe a estar no centro do processo de ensino e de aprendizagem e a assumir um papel ativo na aprendizagem dos assuntos científicos (AUSUBEL; NOVAK; HANESIAN, 1980; PRINCE, 2004). Segundo alguns autores (HMELO-SILVER, 2004; HUNG; JONASSEN; LIU, 2008), uma das abordagens metodológicas que satisfazem esses requisitos é o Ensino Orientado para a Aprendizagem Baseada na Resolução de Problemas (EOABRP), do inglês Problem-Based Learning (PBL).

No EOABRP, os alunos aprendem conhecimentos novos, resolvendo problemas (WOODS, 2000; LAMBROS, 2002). O professor deixa de se apresentar como o detentor do conhecimento a ser aprendedido pelos alunos, para passar a ser um organizador de situações de aprendizagem, desempenhando três papéis principais: criar situações de aprendizagem que estimulem a curiosidade dos alunos e que os façam sentir vontade e necessidade de aprender (LEITE; ESTEVES, 2012); orientar os alunos no processo de aprendizagem (LEITE; AFONSO, 2001; LAMBROS, 2002; HMELO-SILVER, 2004); ajudar os alunos a tomarem consciência do que aprenderam e dos aspectos em que não foram bem-sucedidos, bem como a encontrar formas de colmatar esse insucesso. Assim, no EOABRP, o professor não ensina, no sentido habitual, mas, antes, cria condições para que os alunos aprendam (WOODS, 2000; LEITE; AFONSO, 2001; LAMBROS, 2002; PEDERSON; LIU, 2003). Consequentemente, o papel do aluno também muda profundamente: de ouvinte e receptor de conhecimento, passa a construtor de conhecimento.

As mudanças significativas de papéis que o EOABRP requer fazem com que professores e alunos tenham alguma dificuldade em adaptar-se a essa metodologia. Os primeiros começam por duvidar que os alunos sejam capazes de aprender e sentem vontade de lhes fornecer a informação necessária à resolução do problema (MORGADO, 2013). Os segundos desenvolvem ansiedade pela "resposta correta" (SAHIN, 2009), pretendendo alcançá-la muito rapidamente (SAHIN; YOREK, 2009). Essa ansiedade afeta de modo particular os alunos que 
são considerados (pelos respectivos professores) muito bons alunos, especialmente quando se encontram integrados em turmas heterogêneas (LEITE et al., 2013), pois sentem o fato de terem que procurar o conhecimento a aprender como algo potencialmente ameaçador do seu estatuto acadêmico perante os colegas considerados menos bons alunos. Acresce que os alunos considerados menos bons, ao terem uma oportunidade de aprender de forma diferente da habitual e em ambiente social, adaptam-se bem ao EOABRP, ganham confiança em si mesmos e surpreendem os professores, aproximando-se dos alunos considerados melhores (LEITE et al., 2013). No entanto, depois de ultrapassada a fase de habituação a essa metodologia, a maioria dos alunos, independentemente do seu rendimento acadêmico, apesar de reconhecer que essa metodologia exige mais esforço da parte deles, parece gostar de aprender ciências resolvendo problemas, pelo fato de assumir um papel mais ativo em sala de aula e de poder desenvolver competências que habitualmente não são trabalhadas nas aulas (RIBEIRO; MIZUKAMI, 2005; HATIRUSARU; PEPPER, 2008; KUÇUKTURAN, 2009; SULAIMAN, 2010).

No EOABRP, os problemas são o ponto de partida para a aprendizagem e um dos fatores-chave do sucesso nessa aprendizagem (DAHLGREN, CASTENSSON; DAHLGREN, 1998; LAMBROS, 2002; HMELO-SILVER, 2004; HUNG; JONASSEN; LIU, 2008; PEPPER, 2008), determinando, em grande medida, o que é aprendido. Dado que resolver um problema requer esforço (CHIN; CHIA, 2004), é importante que os alunos sintam que o problema é relevante e que vale a pena resolvê-lo. Para isso, os problemas devem ser reais ou parecer reais (LAMBROS, 2002; CHIN; CHIA, 2004; HMELO-SILVER, 2004; HUNG; JONASSEN; LIU, 2008), o que, consequentemente, significa que devem ser multidisciplinares (HMELO-SILVER, 2004), uma vez que os problemas do dia a dia são abrangentes e que a sua resolução requer a utilização, conjunta, de conhecimentos e competências típicas de diversas áreas disciplinares para serem resolvidos com sucesso. Nesse sentido, se uma dada escola pretender adotar EOABRP, ela terá que encontrar formas de esbater as fronteiras disciplinares, de modo que os saberes tradicionalmente associados às diversas disciplinas possam ser usados e/ou desenvolvidos de forma integrada, consoante as exigências dos problemas selecionados para abordar os diversos temas.

Os problemas podem ser levados para a aula pelo aluno ou pelo professor ou podem ser formulados a partir de contextos problemáticos ou cenários (LEITE et al., 2013). Em qualquer dos casos, tem que ser analisada a sua adequação aos alunos, não só em termos de potencial motivador, mas também em termos da exigência cognitiva (HUNG; JONASSEN; LIU, 2008; BARRET; MOORE, 2011) que comportam. Se esta for muito elevada, provocará desistência; se for muito baixa, causará desmotivação (JONASSEN, 2004; BARRET; MOORE, 2011).

$\mathrm{Na}$ vida real, os problemas podem ter uma ou mais soluções ou podem não ter solução (JONASSEN, 2004). Isso mesmo pode acontecer nas aulas, se os problemas usados forem reais ou semelhantes aos reais. Por isso, os alunos devem desenvolver o hábito de analisar as soluções obtidas, a fim de averiguarem se elas são, ou não, as mais adequadas ao problema em causa, pois, caso não sejam, deverão reiniciar e rever o processo de resolução. Obtida(s) a(s) solução(ões) mais adequada(s) ou, eventualmente, constatado que o problema não tem solução, deverá ser promovida 
uma avaliação do processo de aprendizagem que conduziu a essa conclusão, tanto ao nível individual como ao nível do grupo, a fim de o tornar consciente e explícito e de, assim, reforçar o desenvolvimento de competências de resolução de problemas, por parte dos alunos (LEITE et al., 2013). Dessa forma, o EOABRP, ao colocar o aluno no centro de um processo de aprendizagem de conhecimentos novos a partir da resolução de problemas (tanto quanto possível) reais, facilita a transição do aluno da escola para o mundo social e do trabalho, pois permite-lhe desenvolver competências de aprendizagem ao longo da vida (LAMBROS, 2002; HMELO-SILVER, 2004) que lhe serão úteis enquanto cidadão e enquanto profissional.

No entanto, a investigação não tem conduzido a resultados consensuais no que diz respeito à eficácia do EOABRP para a aprendizagem conceitual. Na verdade, em alguns estudos (SELÇUK, 2010; RUIZ-GALLARDO; CASTAÑO; GÓMEZALDAY; VALDÉS, 2011; RAINE; SYMONS, 2012; SELÇUK; CALIŞKAN; SSAHIN, 2013; HANDE; MOHAMMED; KOMAT'TIL, 2015), constatou-se que alunos submetidos a EOABRP obtiveram melhores resultados do que alunos submetidos a ensino habitual; mas, em outros estudos (ŞAHIN; YOREK, 2009; VASCONCELOS; TORRES, 2013), não foram percebidas diferenças, ao nível da aprendizagem conceitual, entre grupos que usaram e grupos que não usaram EOABRP. Porém, não se identificaram estudos em que alunos submetidos a EOABRP tivessem recebido resultados inferiores aos obtidos por colegas que usaram as metodologias de ensino habituais. Além disso, a eficácia do EOABRP não pode ser avaliada apenas em função dos resultados que produz ao nível conceitual, pois essa é apenas umas das muitas dimensões de aprendizagem que são relevantes numa escola que pretende preparar cidadãos para viver numa sociedade democrática, científica e tecnologicamente avançada. Neste trabalho não focaremos essas outras dimensões (ex.: desenvolvimento de competências de resolução de problemas, de relacionamento interpessoal, etc.) por não serem diretamente relevantes para os objetivos do estudo. No entanto, parece pertinente referir que, a esse nível, há evidências (GANDRA, 2001; SULAIMAN, 2010) de que o EOABRP tem tido mais sucesso do que outras metodologias de ensino. Acresce que é de esperar que o EOABRP, pelas suas caraterísticas, seja mais bem-sucedido em aprendizagens complexas, que são pouco trabalhadas quando são usadas metodologias de ensino tradicionais, do que em aprendizagens simples, que são favorecidas pelo treino e pela repetição. Note-se que estas últimas estratégias não são relevantes no EOABRP, mas são frequentes nas metodologias de ensino tradicionais.

\section{OBJETIVO}

O objetivo geral deste estudo foi comparar os contributos do ensino do tema "Transformação de Matéria e de Energia" orientado para a ABRP, organizado segundo uma abordagem transdisciplinar, com os do ensino tradicional do mesmo tema, no que concerne à aprendizagem de conhecimentos conceituais, com diferentes níveis de complexidade. É deste último aspecto que decorre a principal contribuição deste trabalho, pois há falta de investigação que sustente os argumentos que, a respeito da exigência cognitiva, têm sido avançados por alguns investigadores da área. 


\section{METODOLOGIA DE PESQUISA}

\section{Participantes}

$\mathrm{O}$ estudo centrou-se numa escola secundária com $3^{\circ}$ ciclo, do norte de Portugal, e envolveu 47 alunos de duas turmas do $8^{\circ}$ ano de escolaridade. A Turma Experimental (TE) era constituída por 25 alunos, e a Turma de Controle (TC), por 22 alunos. Qualquer uma das duas turmas tinha números semelhantes de rapazes e moças e quase todos os seus alunos tinham a idade adequada ao ano de escolaridade em causa (13 ou 14 anos). Segundo os respectivos professores de Ciências Físico-Químicas (CFQ) e de Ciências Naturais (CN), as duas turmas eram, também, semelhantes no que diz respeito ao aproveitamento escolar que, atendendo às classificações obtidas pelos alunos no final de período letivo, era por eles considerado razoável. Os dois professores de CFQ e de CN, da TE, bem como os dois professores, das mesmas disciplinas, da TC, eram professores profissionalizados, com mais de 15 anos de serviço, ou seja, eram professores experientes nas disciplinas que lecionavam.

Os alunos da TE e da TC foram informados que estavam participando de um estudo, que era apoiado pela direção da escola e pelos professores de CFQ e de $\mathrm{CN}$ e que o seu anonimato estava garantido. Todos eles acederam a participar.

\section{Intervenção}

Em qualquer uma das duas turmas envolvidas no estudo foi efetuada uma intervenção didática, centrada no tema "Transformação de Matéria e de Energia". Optou-se por esse tema dado que, tal como previsto nas Orientações Curriculares para as Ciências Físicas e Naturais então em vigor (DEB, 2001), contempla assuntos relacionados com situações que ocorrem no dia a dia, o que não só pode motivar os alunos para a sua aprendizagem, mas também o torna adequado para ser abordado segundo EOABRP; e engloba diversos conteúdos, uns pertencentes ao programa de CFQ e outros pertencentes ao programa de $\mathrm{CN}$, o que torna conveniente para abordagens transdisciplinares entre essas duas disciplinas, como exigido pelo objetivo do estudo.

Os alunos da TC estudaram em cada disciplina (CFQ e CN), separadamente, os respectivos assuntos, os quais foram lecionados pelos professores das disciplinas em causa. Os professores seguiram as propostas didáticas apresentadas pelos manuais escolares de CFQ (BELEZA; CAVALEIRO, 2010) e de CN (ANTUNES; BISPO; GUINDEIRA, 2010) adotados na escola em causa, tendo sido um ensino centrado na apresentação de conteúdos pelo professor.

Os alunos da TE estudaram o mesmo tema, não só através de EOABRP, mas também segundo uma abordagem transdisciplinar. Assim, os assuntos e os tempos letivos das duas disciplinas foram reunidos como se pertencessem todos a uma única disciplina. Escolheu-se uma abordagem transdisciplinar na medida em que, segundo Costa (2012), esse nível de integração curricular é o mais compatível com o espírito da Aprendizagem Baseada na Resolução de Problemas. Além disso, alguns autores (HARTLEY; MOMSEN; MASKIEWICZ; D’AVANZO, 
2012) defendem que abordagens integradoras de assuntos relacionados com energia e matéria contribuirão para uma maior compreensão para eles. Essa integração é ainda relevante na medida em que a investigação tem mostrado que diferentes áreas científicas e diferentes manuais escolares (HARTLEY; MOMSEN; MASKIEWICZ; D'AVANZO, 2012) tendem a lidar com esses conceitos de modo diferente e sem promoverem a sua integração, o que pode conduzir à percepção, por parte dos alunos, de que o seu significado depende da disciplina em causa. Nesse contexto, e para atender às condições referidas, elaborou-se, conjuntamente com os dois professores da TE, um cenário, em banda desenhada, intitulado Questões de Sobrevivência, que se pensava suscitar questões cuja resposta exigiria o estudo dos assuntos a lecionar no âmbito do tema selecionado, nas disciplinas de $\mathrm{CN}$ e CFQ, tal como previsto nas Orientações Curriculares para as Ciências Físicas e Naturais (DEB, 2001) então em vigor, a saber: fontes de energia primárias e secundárias; fontes de energia renováveis e não renováveis; transferências e transformações de energia; eficiência energética; cadeias, teias e redes alimentares; ciclo da matéria; fluxo de energia; reprodução; e excreções. Na primeira aula, o cenário foi apresentado aos alunos, a quem foi solicitado que, em grupo, formulassem todas as questões que "a história" nele apresentada lhes suscitasse. Na aula seguinte, as questões foram discutidas em turma, com os objetivos de: clarificar o seu significado; separar questões sem e com interesse científico; e identificar sobreposições entre estas últimas. Do trabalho com estas últimas resultou um conjunto de questões-problema que foram agrupadas por semelhança de assunto. Depois, os professores distribuíram os conjuntos de questões-problemas pelos diferentes grupos de alunos, para que eles as resolvessem, sabendo desde logo que, no final, cada grupo teria que apresentar aos restantes grupos da turma as suas respostas/soluções, atuando como professor dos colegas. Sem prejuízo de os alunos poderem usar outros recursos, foi disponibilizado um conjunto mínimo de fontes bibliográficas, incluindo alguns websites, que eles poderiam consultar. Os professores, para além de assegurarem que os grupos não se dispersavam, desempenharam um papel de facilitador do trabalho do grupo, tentando desbloquear situações, sem dar respostas, mas antes colocando perguntas aos alunos que os levassem a considerar aspectos a que eles não tinham atendido. No final, cada grupo fez uma apresentação do resultado do seu trabalho à turma, oralmente e apoiado por um PowerPoint que elaborou. Após a apresentação, cada grupo foi questionado pelos colegas e pelos professores, com o objetivo de clarificar e/ou explicar melhor as respostas que propuseram para as questões-problemas trabalhadas (ao nível do processo de resolução e da solução obtida), de colmatar eventuais limitações e de esclarecer as dúvidas de colegas. Constatou-se que os alunos da TE, apesar de se terem se envolvido no trabalho, tinham dificuldades em se organizar no trabalho em grupo e na pesquisa e/ou seleção de informação. Por essa razão, o tempo dedicado ao estudo do tema foi um pouco maior (três horas a mais) na TE do que na TC.

\section{Recolha e tratamentos de dados}

De modo a alcançar o objetivo do estudo, foram recolhidos dados através 
de um teste de conhecimentos, que incluía seis questões sobre o tema em estudo (Quadro 1). Para o nível de ensino em causa: três dessas questões (Questões 1, 2 e 3) podem ser consideradas de baixa exigência cognitiva, pois poderiam ser respondidas com base em memorização ou baixa compreensão de conhecimentos; as outras três questões (Questões 4, 5 e 6) podem ser consideradas como tendo exigência cognitiva moderada ou elevada, uma vez que dar-lhes uma resposta correta requer a compreensão e a aplicação de conhecimentos.

Quadro 1 - Estrutura do teste de conhecimentos e exigência das respostas corretas

\begin{tabular}{|c|c|c|c|}
\hline $\begin{array}{l}\text { Exigência } \\
\text { cognitiva }\end{array}$ & $\begin{array}{l}\mathrm{N}^{\circ} \mathrm{da} \\
\text { questão }\end{array}$ & Objetivo da questão & $\begin{array}{l}\text { Ideias que a resposta deve incluir para ser } \\
\text { considerada correta e completa }\end{array}$ \\
\hline \multirow{3}{*}{ Baixa } & {$\left[\begin{array}{c}1 \\
{[a]} \\
e\end{array}\right.$} & $\begin{array}{l}\text { Identificar fontes de } \\
\text { energia: renovável; não } \\
\text { renovável }\end{array}$ & $\begin{array}{l}\text { Fonte de energia: } \\
\text { a) - renovável: sol } \\
\text { b) - não renovável: petróleo/gasóleo }\end{array}$ \\
\hline & 2 & $\begin{array}{l}\text { Pronunciar-se sobre } \\
\text { a necessidade de } \\
\text { substituir combustíveis } \\
\text { fósseis por energia } \\
\text { proveniente do sol }\end{array}$ & $\begin{array}{l}\text { - os combustíveis fósseis esgotar-se-ão em } \\
\text { médio prazo } \\
\text { - os combustíveis fósseis são poluentes } \\
\text { - a energia proveniente do sol não é poluente } \\
\text { - a energia proveniente do sol não se } \\
\text { esgotará em médio prazo }\end{array}$ \\
\hline & 3 & $\begin{array}{l}\text { Explicar a alimentação } \\
\text { dos vermes com base no } \\
\text { seu papel decompositor }\end{array}$ & $\begin{array}{l}\text { - os vermes alimentam-se de matéria } \\
\text { orgânica de seres mortos } \\
\text { - os vermes transformam a matéria orgânica } \\
\text { em matéria mineral } \\
\text { - o processo de transformação designa-se } \\
\text { decomposição, e por isso os vermes são } \\
\text { decompositores }\end{array}$ \\
\hline \multirow{3}{*}{ Elevada } & 4 & $\begin{array}{l}\text { Explicar por que é } \\
\text { que o abandono dos } \\
\text { combustíveis fósseis } \\
\text { contribui para o } \\
\text { desenvolvimento } \\
\text { sustentável do Planeta }\end{array}$ & $\begin{array}{l}\text { - os combustíveis fósseis são poluentes } \\
\text { - o gasóleo é um combustível fóssil, poluente } \\
\text { - a maior parte das fontes de energias } \\
\text { renováveis não é poluente } \\
\text { - a substituição de combustíveis fósseis por } \\
\text { fontes de energia renováveis, não poluentes, } \\
\text { reduz a poluição do meio ambiente } \\
\text { - a redução da poluição é necessária para } \\
\text { que continue a haver condições de vida do } \\
\text { planeta }\end{array}$ \\
\hline & 5 & $\begin{array}{l}\text { Explicar o significado de } \\
\text { "casa com boa eficiência } \\
\text { energética" }\end{array}$ & $\begin{array}{l}\text { - eficiência energética tem a ver com a } \\
\text { relação entre energia aproveitada e energia } \\
\text { recebida } \\
\text { - a casa é tanto mais eficiente quanto maior } \\
\text { for a percentagem da energia recebida que } \\
\text { é utilizada } \\
\text { - a casa deve maximizar a utilização da } \\
\text { energia recebida } \\
\text { - a casa deve minimizar a energia } \\
\text { transferida para o exterior (ou seja, as } \\
\text { (perdas') }\end{array}$ \\
\hline & 6 & $\begin{array}{l}\text { Explicar a importância } \\
\text { da fotossíntese para a } \\
\text { sobrevivência dos seres } \\
\text { vivos }\end{array}$ & $\begin{array}{l}\text { - a fotossíntese origina matéria orgânica que } \\
\text { constitui de alimento para outros seres vivos } \\
\text { - a fotossíntese origina oxigênio essencial } \\
\text { para a vida de alguns seres vivos } \\
\text { - a matéria orgânica produzida na } \\
\text { fotossíntese constitui alimento para a } \\
\text { própria planta } \\
\text { - o oxigênio originado na fotossíntese é } \\
\text { essencial para a própria planta }\end{array}$ \\
\hline
\end{tabular}


O teste, que resultou de consenso entre os autores (investigadores e professores), foi aplicado nos dois grupos de investigação, como pré e pós-teste, respectivamente uma semana antes do início da lecionação do tema e duas semanas após o fim da mesma, por um dos professores de cada turma.

No que concerne à análise de dados, e dado que o teste de conhecimentos incluía questões de resposta aberta e pedidos de justificação, fez-se uma análise de conteúdo das respostas obtidas, tendo as respostas sido classificadas em quatro categorias: resposta Correta, resposta Incompleta, resposta Contendo concepções alternativas e Não responde. Na tabela 1 apresentam-se as ideias que cada resposta deveria conter para poder ser classificada como Correta e, portanto, completa. Respostas em que faltava (m) alguma(s) dessas ideias foram consideradas Incompletas.

Respostas que evidenciassem ter subjacentes ideias cientificamente não aceites foram classificadas na categoria Contendo concepções alternativas. As restantes respostas (incompreensíveis, que não respondiam ao solicitado, em branco, "não sei”) foram incluídas na categoria Não responde. Depois disso, para cada questão, turma e aplicação do teste (pré-teste e pós-teste), foram calculadas frequências relativas por categoria de resposta, de modo a ser possível comparar os dois grupos, que têm dimensões relativamente diferentes. No caso das questões de resposta fechada calculou-se a frequência absoluta e a relativa, por alternativa de resposta. Em qualquer um dos tipos de questão e sempre que se justificava, foi calculado o ganho de cada grupo de investigação, em cada categoria (ganho $=\%$ no pós-teste - \% no pré-teste), a fim de facilitar a comparação da evolução relativa dos grupos. Um ganho positivo pode significar que ocorreu uma alteração desejável (se estiver associado ao aumento das respostas desejáveis, nomeadamente respostas corretas ou completas) ou uma alteração indesejável (se estiver associado ao aumento de respostas não desejadas, nomeadamente respostas contendo concepções alternativas ou não respostas). No caso das respostas incompletas, um ganho positivo pode corresponder a uma alteração desejável (se se dever à diminuição de respostas não desejadas) ou a uma alteração indesejável (se se fizer a custa da diminuição de respostas corretas/desejadas). Em análises subsequentes, centradas nas respostas incluídas na categoria Incompletas, usou-se apenas frequências absolutas devido à, por vezes, muito desigual dimensão dos subgrupos da TC e da TE.

\section{APRESENTAÇÃO E DISCUSSÃO DOS RESULTADOS}

\section{Resultados obtidos com questões de baixo nível cognitivo}

Através da questão 1, os alunos foram solicitados a identificar fontes de energia renovável (a) e não renovável (b). Comparando as respostas obtidas no pré e no pós-teste, constata-se que, nessa questão, não existem diferenças acentuadas entre a evolução dos dois grupos de investigação, como evidenciam os ganhos calculados e apresentados na tabela 1 . Se é verdade que, no caso da identificação de fonte de energia renovável, a TE aumentou (ganho positivo) mais do que a TC, em termos de respostas corretas, a TE regrediu (ganho negativo) um pouco mais do que a TC no caso da identificação de fonte de energia não renovável. 
Tabela 1 - Evolução dos grupos na identificação de fontes de energia renovável e não renovável (\%)

( $N=47$ )

\begin{tabular}{|l|l|c|c|c|c|c|c|}
\hline \multirow{2}{*}{$\begin{array}{c}\text { Fonte de } \\
\text { energia }\end{array}$} & Categoria de resposta & \multicolumn{2}{|c|}{ Pré-teste } & \multicolumn{2}{c|}{ Pós-teste } & \multicolumn{2}{c|}{ Ganho } \\
\cline { 2 - 8 } & Correta & 31,8 & 8,0 & 27,3 & 16,0 & $-4,5$ & 8,0 \\
\hline \multirow{3}{*}{ Renovável } & $\begin{array}{l}\text { Contendo concepções } \\
\text { alternativas }\end{array}$ & 68,2 & 92,0 & 72,7 & 84,0 & 4,5 & $-8,0$ \\
\cline { 2 - 8 } & Não responde & 0,0 & 4,0 & 0,0 & 0,0 & 0,0 & 0,0 \\
\hline \multirow{2}{*}{$\begin{array}{l}\text { Não } \\
\text { renovável }\end{array}$} & Correta & 68,2 & 72,0 & 68,2 & 68,0 & 0,0 & $-4,0$ \\
\cline { 2 - 8 } & $\begin{array}{l}\text { Contendo concepções } \\
\text { alternativas }\end{array}$ & 18,2 & 12,0 & 13,6 & 20,0 & $-4,6$ & 8,0 \\
\cline { 2 - 8 } & Não responde & 13,6 & 16,0 & 18,2 & 12,0 & 4,6 & $-4,0$ \\
\hline
\end{tabular}

Nota: $\mathrm{n}_{\mathrm{TC}}=22 ; \mathrm{n}_{\mathrm{TE}}=25$

Em ambos os grupos de investigação, um elevado número de alunos evidenciou concepções alternativas aquando da identificação das fontes de energia em causa. Essas conceções estão relacionadas com o fato de os alunos parecerem não distinguir fontes de energia de tipos de energia, pelo que, em vez de referirem, por exemplo, que a fonte de energia renovável é o sol, dizem que a fonte é "a energia solar". Esses resultados, que podem ter muito a ver com linguagem cotidiana, são compatíveis com o relato apresentado por Kurnaz e Sağlam-Arslan (2011) que refere essa não diferenciação por parte de alunos turcos, do ensino básico.

Os alunos foram solicitados a pronunciar-se sobre a eventual necessidade de substituir os combustíveis fósseis por energia proveniente do sol, a fim de contribuir para o desenvolvimento sustentável do planeta (Questão 2). Do pré para o pós-teste, verificou-se uma diminuição de não respondentes, nas duas turmas (Tabela 2), o que significa que aumentou o número de alunos que passaram a explicitar uma opinião sobre o assunto.

Tabela 2 - Evolução dos grupos no que diz respeito à necessidade de substituir os combustíveis fósseis por energia proveniente do sol (\%)

( $N=47)$

\begin{tabular}{|l|c|c|c|c|c|c|}
\hline \multirow{2}{*}{$\begin{array}{c}\text { Substituição dos } \\
\text { combustiveis fósseis }\end{array}$} & \multicolumn{2}{|c|}{ Pré-teste } & \multicolumn{2}{c|}{ Pós-teste } & \multicolumn{2}{c|}{ Ganho } \\
\cline { 2 - 7 } Não é necessário & TC & TE & TC & TE & TC & TE \\
\hline É necessário & 13,6 & 12,0 & 9,1 & 8,0 & $-4,5$ & $-4,0$ \\
\hline Não responde & 68,2 & 76,0 & 81,8 & 84,0 & 13,6 & 8,0 \\
\hline
\end{tabular}

Nota: $\mathrm{n}_{\mathrm{TC}}=22 ; \mathrm{n}_{\mathrm{TE}}=25$ 
Além disso, constata-se que, em ambos os grupos, houve uma diminuição dos respondentes que não consideravam ser necessária essa substituição, como evidenciam os respectivos ganhos negativos. Consequentemente, tanto a TC como a TE evoluíram (embora a TC tenha evoluído um pouco mais do que a TE) no que concerne ao posicionamento correto (reconhecimento da necessidade de substituir os combustíveis fósseis por energia proveniente do sol), como ilustram os valores dos respectivos ganhos positivos.

Tanto antes como após a intervenção, os alunos, de ambas as turmas, que mencionaram que não havia necessidade de efetuar a substituição dos combustíveis fósseis, referiram que "os combustíveis ainda vão durar muitos anos", o que traduz uma ideia errada de inesgotabilidade desse tipo de recurso energético, a qual havia já sido identificada por Vieira (2007) em alunos do mesmo nível de escolaridade.

Analisando as justificações dos alunos que defenderam a necessidade de substituir os combustíveis fósseis pela energia proveniente do sol, à luz dos critérios mencionados no quadro 1, constata-se que não houve respostas corretas, em nenhuma das turmas, nem no pré nem no pós-teste (Tabela 3). No que concerne às respostas incompletas, houve um aumento nos respectivos números, nas duas turmas, sendo este maior na TE.

Tabela 3 - Evolução dos posicionamentos favoráveis à substituição dos combustíveis fósseis por energia proveniente do sol ( $\mathrm{f}$ )

\begin{tabular}{|l|c|c|c|c|}
\hline \multirow{2}{*}{ Categorias de resposta } & \multicolumn{2}{c|}{ Pré - teste } & \multicolumn{2}{c|}{ Pós - teste } \\
\cline { 2 - 5 } & $\begin{array}{c}\mathrm{TC} \\
(\mathrm{n}=15)\end{array}$ & $\begin{array}{c}\mathrm{TE} \\
(\mathrm{n}=19)\end{array}$ & $\begin{array}{c}\mathrm{TC} \\
(\mathrm{n}=18)\end{array}$ & $\begin{array}{c}\mathrm{TE} \\
(\mathrm{n}=21)\end{array}$ \\
\hline Correta & 0 & 0 & 0 & 0 \\
\hline Incompleta & 7 & 10 & 9 & 14 \\
\hline Contendo Conceções alternativas & 1 & 1 & 1 & 1 \\
\hline Não responde & 7 & 8 & 8 & 6 \\
\hline
\end{tabular}

Nesses tipos de respostas, antes e após a intervenção, na TC a maioria dos alunos apenas mencionou um dos quatros aspectos considerados necessários para que a resposta fosse classificada como correta, enquanto que, na TE, isso só aconteceu antes da intervenção (Tabela 4). Na verdade, após a intervenção, na TE, houve um aumento do número de alunos que mencionaram dois ou mais aspectos. É de se notar que o aspecto referido por mais alunos, em ambas as turmas, foi o que afirma que os combustíveis fósseis são poluentes, o que, na verdade, explica pouco acerca da necessidade de substituir os referidos combustíveis. As respostas, incompletas, que se seguem (com negrito adicionado pelos autores deste texto) ilustram uma evolução dentro dessa categoria, do pré para o pós-teste. 
Se os combustiveis fósseis não forem substituídos urgentemente, vão continuar a poluir os mares e o ar, piorando a situação ambiental do Planeta." (Pré TE18)

Os combustiveis fosseis esgotam-se e poluem e para preservar o Planeta devemos ter uma gestão dos resíduos e recorrer a "combustiveis limpos" e a energia renováveis, como a solar. (Pós TE18).

Tabela 4 - Número de elementos incluídos nas respostas incompletas, favoráveis à substituição dos combustíveis fósseis por energia proveniente do sol (f)

\begin{tabular}{|l|c|c|c|c|}
\hline \multirow{2}{*}{ Número de elementos } & \multicolumn{2}{|c|}{ Pré-teste } & \multicolumn{2}{c|}{ Pós-teste } \\
\cline { 2 - 5 } & $\begin{array}{c}\text { TC } \\
(n=7)\end{array}$ & $\begin{array}{c}\text { TE } \\
(n=10)\end{array}$ & $\begin{array}{c}\text { TC } \\
(n=9)\end{array}$ & $\begin{array}{c}\text { TE } \\
(n=14)\end{array}$ \\
\hline Um & 7 & 6 & 7 & 6 \\
\hline Dois & 0 & 3 & 2 & 6 \\
\hline Três & 0 & 1 & 0 & 2 \\
\hline
\end{tabular}

Fonte: Elaboração dos autores.

Por outro lado, constatou-se que algumas respostas parecem ter subjacentes concepções alternativas, especialmente relacionadas com as energias renováveis que são percecionadas como sendo todas não poluentes. Delas é exemplo a seguinte resposta: "Acho que a melhor opção é investir nas energias renováveis, pois não se esgotarão e não fazem mal ao ambiente" (Pré TE16).

Nessa resposta, o autor explicita a necessidade de substituir os combustíveis fósseis por energias renováveis, mas evidencia a ideia de que as energias renováveis não são poluentes, o que não é verdade, pois, como se sabe, a biomassa é uma fonte de energia renovável, mas poluente. Aquela ideia corresponde a uma concepção alternativa que havia já sido identificada por Vieira (2007), em alunos do mesmo ano de escolaridade.

A Questão 3 solicitava aos alunos que explicassem a alimentação dos vermes com base no seu papel decompositor. Os dados apresentados na tabela 5 mostram que, do pré para o pós-teste, houve uma diminuição de não respondentes, nas duas turmas, sendo essa diminuição maior na TC (ganho mais negativo), o que, em consequência, significa que aumentou o número de alunos que passaram a conseguir explicar a alimentação dos vermes. No entanto, quer antes ou após as intervenções, em ambas as turmas, não houve respostas corretas, ou seja, respostas que satisfizessem todos os critérios referidos no quadro 1. Registrouse, contudo, uma evolução, em ambas as turmas, evidenciada, sobretudo, pelas respostas incompletas. No cômputo geral, essa evolução é muito semelhante nas duas turmas, embora ligeiramente favorável à TC (Tabela 5) que apresentou um ganho ligeiramente superior ao da TE, nesse tipo de resposta. 
Tabela 5 - Evolução dos grupos na explicação da alimentação dos vermes (\%)

( $\mathrm{N}=\mathbf{4 7 )}$

\begin{tabular}{|l|c|c|c|c|c|c|}
\hline \multirow{2}{*}{ Categoria de resposta } & \multicolumn{2}{|c|}{ Pré-teste } & \multicolumn{2}{c|}{ Pós-teste } & \multicolumn{2}{c|}{ Ganho } \\
\cline { 2 - 7 } & TC & TE & TC & TE & TC & TE \\
\hline Completa & 0,0 & 0,0 & 0,0 & 0,0 & 0,0 & 0,0 \\
\hline Incompleta & 0,0 & 24,0 & 54,5 & 76,0 & 54,5 & 52,0 \\
\hline $\begin{array}{l}\text { Contendo concepções } \\
\text { alternativas }\end{array}$ & 0,0 & 16,0 & 13,6 & 4,0 & 13,6 & $-12,0$ \\
\hline Não responde & 100,0 & 60,0 & 31,8 & 20,0 & $-68,2$ & $-40,0$ \\
\hline
\end{tabular}

Nota: $\mathrm{n}_{\mathrm{TC}}=22 ; \mathrm{n}_{\mathrm{TE}}=25$

Apesar de, em ambos os grupos de investigação, a maioria desses alunos mencionar apenas um dos elementos da resposta correta (Tabela 6), constata-se que a TE apresenta, no pós-teste, um número superior de respostas mais completas. Verifica-se, ainda, que, em ambos os grupos de investigação, um dos elementos mencionados em mais respostas incompletas dos alunos foi "os vermes alimentamse de matéria orgânica de seres mortos", que, embora sendo um dos elementos informativos a incluir na resposta correta, não é suficiente para explicar o que se pretendia. O exemplo que se segue ilustra esse tipo de resposta: "[A pele] serve para alimentar os vermes, pois estes vão decompor matéria orgânica de que se alimentam." (Pós TE18).

Tabela 6 - Número de elementos incluídos nas respostas incompletas sobre a alimentação dos vermes (f)

\begin{tabular}{|l|c|c|c|c|}
\hline \multirow{2}{*}{ Número de elementos } & \multicolumn{2}{|c|}{ Pré-teste } & \multicolumn{2}{c|}{ Pós-teste } \\
\cline { 2 - 5 } & $\begin{array}{c}\text { TC } \\
(n=0)\end{array}$ & $\begin{array}{c}\text { TE } \\
(n=6)\end{array}$ & $\begin{array}{c}\text { TC } \\
(n=12)\end{array}$ & $\begin{array}{c}\text { TE } \\
(n=19)\end{array}$ \\
\hline Um & 0 & 6 & 10 & 14 \\
\hline Dois & 0 & 0 & 2 & 5 \\
\hline
\end{tabular}

Fonte: Elaboração dos autores.

No caso das respostas contendo concepções alternativas (Tabela 5), constatase que, do pré para o pós-teste, houve uma diminuição desse tipo de resposta, na TE, e um aumento na TC. Essas concepções estão relacionadas com o fato de os alunos considerarem que os vermes só se alimentam de matéria orgânica já em decomposição e que esta os atrai. Esse aspecto pode ser ilustrado pelo exemplo de resposta que se segue: "A pele fica em decomposição e atrai vermes que a devoram para sobreviver" (Pré TE20). E: "Os vermes comem carne em decomposição" (Pós TC20).

Note-se que não se encontrou na literatura consultada relato da concepção 
de que os vermes se alimentam de matéria orgânica que já estivesse em decomposição, em vez de serem eles a promoverem essa decomposição. No entanto, essa ideia pode estar relacionada com o fato de, como foi constatado em estudantes com idades semelhantes (CARVALHO; NELO; SANTOS; NASCIMENTO; COSTA, 2014), os participantes no presente estudo terem dificuldade em identificar o que os consumidores comem e acreditarem que tudo o que morre vai para o solo e depois desaparece, aparentemente sem a intervenção dos decompositores. Por seu lado, a concepção de que a matéria orgânica em decomposição atrai os vermes pode significar uma concepção animista. Como constataram outros autores, os alunos parecem ter ideias pouco claras acerca do que são os vermes e do seu papel na decomposição da matéria (ZOMPERO; LABURU, 2010), podendo não os distinguir de microrganismos (ZOMPERO, 2009) ou de outros animais muito pequenos causadores de doenças (CASTRO; BEJARANO, 2012), o que pode ajudar a compreender as dificuldades dos alunos em responder à questão em causa.

Em síntese, e atendendo aos dados anteriormente apresentados, constatase que: na pergunta 1, o EOABRP conduziu a resultados semelhantes aos obtidos com o ensino tradicional (tabelas 1 e 2); na pergunta 2, o EOABRP conduziu a resultados piores do que os obtidos com o ensino tradicional (tabela 3); na pergunta 3 o EOABRP conduziu a resultados ligeiramente melhores do que os obtidos com o ensino tradicional (tabela 5). Assim, no cômputo geral, os resultados obtidos sugerem que, no caso de questões que exigem a mera memorização dos assuntos em que incidem, o EOABRP parece conduzir a resultados semelhantes aos do ensino tradicional. Esses resultados, que eram esperados, são compatíveis com os obtidos previamente em outros estudos realizados por autores como Selçuk (2010), Ruiz-Gallardo, Castaño, Gómez-Alday e Valdés (2011), Raine e Symons (2012), Selçuk, Calişkan e Şahin (2013) e Hande, Mohammed e Komattil (2015). Para além dessa conclusão geral, constatou-se, ainda, que, após o ensino, as respostas incompletas, na TE, foram um pouco menos incompletas do que na TC e que algumas concepções alternativas resistiram ao ensino e/ou surgiram na sequência deste, mas mantendo conteúdo semelhante ao que apresentavam antes do ensino, em qualquer um dos grupos.

\section{Resultados obtidos com questões de elevado nível cognitivo}

Os alunos foram solicitados a explicar por que o abandono dos combustíveis fósseis contribui para o desenvolvimento sustentável do planeta (Questão 4). De acordo com os dados apresentados na tabela 7, constata-se que, nem no pré nem no pós-teste, houve respostas corretas em nenhum dos grupos, e que, após o ensino, a percentagem de não respostas permaneceu relativamente elevada, especialmente na TC. Contudo, na TE, houve um aumento considerável das respostas incompletas (ganho positivo), o que evidencia consciência das consequências do uso de combustíveis fósseis, bem como dos benefícios do recurso a fontes de energias renováveis, não poluentes. No entanto, não de verificam grandes diferenças no que concerne ao grau de completude dessas respostas na medida em que o número de respostas com mais de um elemento é muito reduzido e pouco diferente nos dois grupos (Tabela 8). 
Tabela 7 - Evolução dos grupos sobre a contribuição do abandono de combustíveis fósseis para 0 desenvolvimento sustentável do Planeta (\%)

$(\mathrm{N}=\mathbf{4 7})$

\begin{tabular}{|l|c|c|c|c|c|c|}
\hline \multirow{2}{*}{ Categoria de resposta } & \multicolumn{2}{|c|}{ Pré-teste } & \multicolumn{2}{c|}{ Pós-teste } & \multicolumn{2}{c|}{ Ganho } \\
\cline { 2 - 7 } & TC & TE & TC & TE & TC & TE \\
\hline Correta & 0,0 & 0,0 & 0,0 & 0,0 & 0,0 & 0,0 \\
\hline Incompleta & 36,4 & 32,0 & 36,4 & 64,0 & 0,0 & 32,0 \\
\hline $\begin{array}{l}\text { Contendo concepções } \\
\text { alternativas }\end{array}$ & 4,5 & 28,0 & 18,2 & 16,0 & 13,6 & $-12,0$ \\
\hline Não responde & 59,1 & 40,0 & 45,4 & 20,0 & $-13,6$ & $-20,0$ \\
\hline
\end{tabular}

Nota: $\mathrm{n}_{\mathrm{TC}}=22 ; \mathrm{n}_{\mathrm{TE}}=25$

Acresce que, após as intervenções, as respostas incompletas apresentadas pelos alunos de ambas as turmas centraram-se numa ideia geral, de fácil memorização: o gasóleo é poluente. Contudo, algumas respostas incompletas apresentadas pelos alunos da TE focaram-se mais na interligação entre ideias diferentes (ex.: substituição de fontes de energia não renováveis por fontes de energia renováveis e contribuição dessa substituição para a redução da poluição do meio ambiente) que são duas das ideias necessárias para que a resposta seja considerada correta. Essas respostas podem ser ilustradas pelo exemplo: "Sim, pois, ao deixar de utilizar o gasóleo, estará contribuindo para que se utilizem menos energias não renováveis e não esteja poluindo [tanto] o ambiente" (Pós TE19).

Tabela 8 - Número de elementos das respostas incompletas sobre a contribuição do abandono de combustíveis fósseis para o desenvolvimento sustentável do planeta (f)

\begin{tabular}{|l|c|c|c|c|}
\hline \multirow{2}{*}{ Número de elementos } & \multicolumn{2}{|c|}{ Pré-teste } & \multicolumn{2}{c|}{ Pós-teste } \\
\cline { 2 - 5 } & $\begin{array}{c}\text { TC } \\
(n=8)\end{array}$ & $\begin{array}{c}\text { TE } \\
(n=8)\end{array}$ & $\begin{array}{c}\text { TC } \\
(\mathbf{n}=8)\end{array}$ & $\begin{array}{c}\text { TE } \\
(n=16)\end{array}$ \\
\hline Um & 8 & 7 & 7 & 13 \\
\hline Dois & 0 & 1 & 1 & 3 \\
\hline Três & 0 & 0 & 0 & 0 \\
\hline Quatro & 0 & 0 & 0 & 0 \\
\hline
\end{tabular}

Fonte: Elaboração dos autores.

Em relação às respostas contendo concepções alternativas, constata-se que, em ambas as turmas, elas estão relacionadas com o fato de os alunos parecerem 
não distinguir fontes de energia de tipos de energia (falando, por exemplo, em energia renovável em vez de falarem em fonte de energia renovável ou em energia que não se esgota em vez de falarem em fonte de energia que não se esgota) ou de considerarem que todas as energias renováveis são não poluentes, pois fazem afirmações sobre o caráter não poluente das (todas) energias renováveis, em vez de limitarem a sua afirmação às que são, de fato, não poluentes. Essas concepções, que haviam já emergido aquando da análise das respostas dadas pelos alunos às questões 1 e 2, podem ser ilustradas pelos exemplos que se seguem:

Ao deixar de utilizar o gasóleo, que é um derivado de um combustivel fóssil que é uma fonte de energia não renovável, desde que substitua por uma energia renovável, está contribuindo para o desenvolvimento sustentável do planeta, devem ser utilizadas energias que não se esgotam (ou que se formem mais rápido do que se gastam), por exemplo a solar. (Pós TE11).

[Ao deixar de utilizar o gasóleo está contribuindo para o desenvolvimento sustentável do planeta], porque o gasóleo é uma fonte de energia poluente e trocar por uma fonte de energia renovável seria a melhor escolha. (Pós TC14).

No global, esses resultados são favoráveis à metodologia de ensino utilizada na TE, ou seja, ao EOABRP.

Através da questão 5, os alunos foram questionados sobre o que significa dizer que uma casa possui boa eficiência energética. Analisando a evolução do pré para o pós-teste, constata-se que, em qualquer um dos grupos de investigação, continuaram a não existir respostas corretas e que o número de não respostas continuou elevado (superior a 50\% em ambos os grupos), tendo havido uma pequena diminuição na TC e um pequeno aumento na TE (Tabela 9).

Tabela 9 - Evolução dos grupos acerca do significado de "casa com boa eficiência energética" (\%)

$(\mathrm{N}=\mathbf{4 7 )}$

\begin{tabular}{|l|c|c|c|c|c|c|}
\hline \multirow{2}{*}{ Categoria de resposta } & \multicolumn{2}{|c|}{ Pré-teste } & \multicolumn{2}{c|}{ Pós-teste } & \multicolumn{2}{c|}{ Ganho } \\
\cline { 2 - 7 } & TC & TE & TC & TE & TC & TE \\
\hline Completa & 0,0 & 0,0 & 0,0 & 0,0 & 0,0 & 0,0 \\
\hline Incompleta & 0,0 & 8,0 & 9,1 & 20,0 & 9,1 & 12,0 \\
\hline $\begin{array}{l}\text { Contendo Concepções } \\
\text { alternativas }\end{array}$ & 36,4 & 28,0 & 36,4 & 12,0 & 0,0 & $-16,0$ \\
\hline Não responde & 63,6 & 64,0 & 54,5 & 68,0 & $-9,1$ & 4,0 \\
\hline
\end{tabular}

Nota: $\mathrm{n}_{\mathrm{TC}}=22 ; \mathrm{n}_{\mathrm{TE}}=25$

Fonte: Elaboração dos autores.

Note-se que, nesta questão, as respostas incluídas na categoria Não responde incluem respostas de alunos que, em vez de referirem o que significa dizer que uma casa 
tem boa eficiência energética, referiram uma espécie de medidas para "economizar" energia. Apresentam-se, de seguida, dois exemplos desse tipo de respostas:

Que ao utilizar a energia solar (através de painéis solares) está poupando dinheiro, pois não precisa de gastar energias não renováveis. (Pós TE13).

\section{[...] boa eficiência energética quer dižer que não gastem muita energia. (Pós TC16).}

Nas duas turmas, do pré para o pós-teste, registrou-se um ligeiro aumento das respostas incompletas, que foi ligeiramente superior na TE. Nessa turma, o aumento fez-se à custa das respostas contendo concepções alternativas, enquanto que na TC se deveu à redução das não respostas (tabela 9). Acresce que na TE as respostas incompletas são menos incompletas (contêm mais elementos) como se pode ver na tabela 10 . De seguida apresenta-se um exemplo de resposta incompleta, que refere a maximização do rendimento, aliada à minimização da dissipação, mas que omite a ideia de que a casa deve minimizar as perdas para o exterior: "Boa eficiência energética significa que a casa tira o maior partido da fonte de energia a que está sujeita, a energia dissipada é menor" (Pós TE3).

Nas respostas incompletas, o elemento mais referido foi: a casa deve maximizar a utilização da energia recebida; os dois primeiros elementos explicitados no quadro 1 como sendo necessários para que a resposta fosse correta não foram mencionados por nenhum dos grupos de investigação, o que significa que os autores dessas respostas não usaram o conceito de rendimento nem outros conceitos com ele relacionados.

Tabela 10 - Número de elementos das respostas incompletas sobre significado de "casa com boa eficiência energética" (f)

\begin{tabular}{|l|c|c|c|c|}
\hline \multirow{2}{*}{ Número de elementos } & \multicolumn{2}{|c|}{ Pré-teste } & \multicolumn{2}{c|}{ Pós-teste } \\
\cline { 2 - 5 } & $\begin{array}{c}\mathrm{TC} \\
(\mathrm{n}=0)\end{array}$ & $\begin{array}{c}\mathrm{TE} \\
(\mathrm{n}=2)\end{array}$ & $\begin{array}{c}\mathrm{TC} \\
(\mathrm{n}=2)\end{array}$ & $\begin{array}{c}\mathrm{TE} \\
(\mathrm{n}=5)\end{array}$ \\
\hline Um & 0 & 1 & 2 & 1 \\
\hline Dois & 0 & 1 & 0 & 4 \\
\hline Três & 0 & 0 & 0 & 0 \\
\hline
\end{tabular}

Fonte: Elaboração dos autores.

Foram ainda identificadas algumas respostas que parecem ter subjacentes concepções alternativas, nomeadamente: os painéis solares acumulam energia solar; e ser energeticamente eficiente é usar energias renováveis. Essas concepções podem ser ilustradas pelas duas respostas que se seguem:

Porque os painéis solares acumulam a energia solar e, assim, uma casa tem sempre a energia solar. (Pós TE4). 
A primeira dessas conceções tem subjacente a ideia, previamente identificada em diversos estudos (DRIVER; SQUIRES; RUSHWORTH; WOOD-ROBINSON, 1994), de que a energia proveniente do sol é como uma matéria ou combustível que se pode armazenar, e, nesse caso, por comparação com o referido por Ferreira (2014), pode dever-se à não compreensão do funcionamento dos coletores e dos painéis solares. A segunda concepção pode ter a ver com o fato de os alunos, do mesmo modo que associam coisas más (DOVE, 1996; ÇIMER, S.; ÇIMER, A; URSAVAŞ, 2011), tenderem a associar duas coisas que eles pensam que são boas, apesar de não saberem bem o que é nenhuma delas: energias renováveis e eficiência energética.

De um modo global, esses resultados sugerem que, apesar de não terem sido alcançadas respostas completas, a TE evoluiu um pouco mais do que a TC, pelo que o EOABRP parece ter sido ligeiramente mais vantajoso do que o ensino tradicional.

Os alunos foram, ainda, solicitados a explicar a relevância da fotossíntese para a sobrevivência dos seres vivos (Questão 6). Não houve respostas corretas em nenhum dos grupos de investigação, nem no pré nem no pós-teste (Tabela 11). Do pré para o pós-teste, houve uma considerável diminuição dos não respondentes, na TC, e uma ligeira diminuição na TE. No caso das respostas incompletas, do pré para o pósteste, houve um grande aumento destas na TC, e um pequeno aumento da respectiva porcentagem na TE. Note-se que nesse último grupo, no pré-teste, as porcentagens de respostas incompletas da TE eram muito superiores às da TC, o que fazia com que essa turma pudesse evoluir muito mais que a TE dentro da categoria em causa.

Tabela 11 - Evolução dos grupos sobre a relevância da fotossíntese para sobrevivência dos seres vivos (\%)

( $N=47)$

\begin{tabular}{|l|c|c|c|c|c|c|}
\hline \multirow{2}{*}{ Categoria de resposta } & \multicolumn{2}{|c|}{ Pré-teste } & \multicolumn{2}{c|}{ Pós-teste } & \multicolumn{2}{c|}{ Ganho } \\
\cline { 2 - 7 } & TC & TE & TC & TE & TC & TE \\
\hline Completa & 0,0 & 0,0 & 0,0 & 0,0 & 0,0 & 0,0 \\
\hline Incompleta & 31,8 & 68,0 & 77,3 & 72,0 & 45,5 & 4,0 \\
\hline Contendo concepções & 18,2 & 16,0 & 9,1 & 16,0 & $-9,1$ & 0,0 \\
\hline $\begin{array}{l}\text { Não responde/ Não } \\
\text { sabe }\end{array}$ & 50,0 & 16,0 & 13,6 & 12,0 & $-36,4$ & $-4,0$ \\
\hline
\end{tabular}

Nota: $\mathrm{n}_{\mathrm{TC}}=22 ; \mathrm{n}_{\mathrm{TE}}=25$

Fonte: Elaboração dos autores.

Verifica-se, no entanto, que na TE, no pós-teste, algumas das respostas incompletas tornaram-se um pouco mais completas (Tabela 12) do que na TC, na medida em que naquela turma se obtiveram maiores números de alunos a apresentar respostas com dois ou três dos elementos exigidos para a resposta poder ser considerada correta (ver Quadro 1) do que na TC. 
Tabela 12 - Número de elementos incluídos nas respostas incompletas sobre a relevância da fotossíntese para sobrevivência dos seres vivos (f)

\begin{tabular}{|l|c|c|c|c|}
\hline \multirow{2}{*}{ Número de elementos } & \multicolumn{2}{|c|}{ Pré-teste } & \multicolumn{2}{c|}{ Pós-teste } \\
\cline { 2 - 5 } & $\begin{array}{c}\text { TC } \\
(n=7)\end{array}$ & $\begin{array}{c}\text { TE } \\
(n=17)\end{array}$ & $\begin{array}{c}\text { TC } \\
(n=17)\end{array}$ & $\begin{array}{c}\text { TE } \\
(n=18)\end{array}$ \\
\hline Um & 7 & 7 & 10 & 6 \\
\hline Dois & 0 & 10 & 7 & 11 \\
\hline Três & 0 & 0 & 0 & 1 \\
\hline
\end{tabular}

Todos os elementos necessários para que uma resposta fosse considerada correta (Quadro 1) foram mencionados pelos dois grupos, quer no pré quer no pósteste, com exceção do elemento que diz que "o oxigênio é essencial para a própria planta", o que, como havia sido constatado por Keleş e Kefelib (2010), pode indiciar que os alunos não tinham consciência de que a planta também necessita de oxigênio (para efetuar a respiração). O elemento incluído em maior número de respostas incompletas, nos dois grupos, foi "a fotossíntese origina oxigênio essencial para a vida de alguns seres vivos". A ideia de que a matéria orgânica produzida pelas plantas (também) constitui alimento para as próprias plantas foi explicitada por um número muito maior de alunos to TE (12) do que da TC (seis) no pós-teste, o que pode evidenciar uma maior qualidade das aprendizagens realizadas por aquele grupo. Note-se que, como referem Driver, Squires, Rushworth e Wood-Robinson (1994), a ideia de que a matéria orgânica produzida pela planta constitui o seu próprio alimento é uma ideia muito difícil de aceitar por crianças e jovens.

Por outro lado, no que concerne às respostas contendo concepções alternativas, verifica-se que, do pré para o pós-teste, houve uma diminuição desse tipo de respostas na TC (ganho negativo) e uma permanência em termos percentuais, na TE (Tabela 11). Contudo, em qualquer uma das turmas identificaram-se concepções alternativas já descritas em outros estudos (DRIVER; SQUIRES; RUSHWORTH; WOOD-ROBINSON, 1994; KELEŞ; KEFELIB, 2010; KÖSE, 2008), as quais se explicitam e ilustram de seguida:

i) Ar é o mesmo que oxigênio

"Porque a fotossintese produz o ar que respiramos." (Pré TC5)

ii) A fotossíntese é o inverso da respiração

"As plantas respiram [inspiram] dióxido de carbono e expiram oxigênio." (Pré TC14)

iii) A fotossíntese purifica o ar

"Porque a [função da] fotossintese é purificar o ar." (Pré TE22) 
iv) A realização da fotossíntese necessita de energia solar

"Porque sem energia solar não haveria fotossintese." (Pré TC8)

v) Todos os seres vivos precisam de oxigênio

"Sem fotossintese não haveria oxigénio e se não houvesse oxigénio não haveria vida." (Pós TE7).

Os resultados obtidos com essa questão são ligeiramente favoráveis à TC, o que poderia significar que, nesse caso, o EOABRP conduziu a resultados menos bons do que o ensino tradicional. No entanto, uma vez que a TE partiu em muita vantagem (partiu de 68,0\%), comparativamente com a TC (partiu de 31,8\%) não se pode ter muita segurança nessa afirmação, pois a TE já só podia progredir 32,0\% enquanto que a TC podia progredir $68,2 \%$. Por outro lado, é também possível que os conteúdos associados a essa questão tenham exigências cognitivas especialmente elevadas. Na verdade, e ao contrário do que seria de se esperar, pelo menos na TE, nenhum aluno, de nenhuma das turmas, alcançou respostas completas. Isso pode significar que os alunos, incluindo os da TE que, à partida, pareciam dominar melhor o assunto, não conseguiram alcançar uma compreensão suficientemente elevada deste, que lhes permitisse passar a responder de forma completa à referida questão.

Em suma, considerando as três questões a que estão associadas aprendizagens conceituais mais exigentes, os dados apresentados nas tabelas 7 e 9 sugerem que o EOABRP pode ter sido mais eficaz do que o ensino tradicional nas questões 4 e 5, não se podendo concluir com segurança sobre o que se passou na questão 6 , com base nos dados apresentados na tabela 11, talvez porque a aprendizagem de assuntos muito complexos exige a intervenção mediadora do professor.

\section{CONCLUSÕES E IMPLICAC̣ÕES}

O objetivo geral deste estudo foi comparar os contributos do EOABRP, organizado segundo uma abordagem transdisciplinar, e do ensino tradicional, no que concerne à aprendizagem de conhecimentos conceituais, com diferentes níveis de complexidade, do âmbito do tema "Transformação de Matéria e Energia". No que concerne às aprendizagens de conhecimentos conceituais realizadas pelos alunos, constatou-se que, em ambas as turmas, os alunos raramente alcançaram respostas completas, fato que pode dever-se, pelo menos em parte, à considerável exigência colocada para que uma resposta pudesse ser classificada como correta. Além disso, de um modo geral, os alunos da TE obtiveram melhor desempenho do que os alunos da TC em questões de mais elevada exigência cognitiva, que requerem uma maior interligação de diferentes conhecimentos conceituais, passando-se o contrário nas questões conceitualmente menos exigentes. Assim, o EOABRP parece ser algo vantajoso no caso das aprendizagens moderadamente complexas, mas não parece ser muito vantajoso em questões cuja resposta exige apenas a "mera" memorização de conhecimentos conceituais, nem em questões de bastante elevada exigência cognitiva (como é o caso da questão 6). Esses resultados parecem ser compatíveis com os resultados esperados com base nas características e nas potencialidades desse tipo de ensino, bem como à luz das 
diferenças entre os resultados dos trabalhos de investigação referidos na parte inicial deste texto. Contudo, as pequenas diferenças entre os resultados obtidos pelos dois grupos, a reduzida dimensão da amostra, o fato de o EOABRP constituir uma novidade para professores e alunos, a falta de habituação dos alunos a trabalho em grupo e a pesquisa, a seleção e a utilização de informação são alguns dos fatores que fazem com que não seja possível fazer generalizações nem mesmo tirar conclusões seguras com base nos resultados obtidos. No entanto, o fato de os resultados obtidos estarem alinhados com o que se esperava dá suporte à ideia de que o estudo deve ser replicado de modo a obter, ou não, mais suporte para a nossa hipótese de trabalho. De qualquer forma, vale a pena recordar que a eficácia do EOABRP não pode ser avaliada apenas em função dos resultados que produz ao nível das aprendizagens de conhecimentos conceituais. O EOABRP pode ser usado para os alunos aprenderem a aprender ciências, mas é necessário investigar, entre outras, as seguintes questões a fim de entender melhor por que os alunos não aprofundaram mais as aprendizagens conceituais relacionadas com esse tema: será que eles sentiam que já sabiam tudo sobre o tema em causa? Ou será que as fontes de informação que consultaram não foram capazes de impulsioná-los a ir mais ao fundo da questão? Ou será, ainda, que o teste de conhecimentos utilizado na investigação e/ou os critérios de correção tinha(m) um nível de exigência maior do que aquele a que os alunos estavam habituados?

\section{Agradecimentos}

Trabalho realizado no âmbito do projeto Educação em Ciências para a Cidadania através da Aprendizagem Baseada na Resolução de Problemas (PTDC/CPE-CED/108197/2008), financiado pela FCT e sediado no Centro de Investigação em Educação (CIEd/FCT-Portugal). Os autores agradecem à escola onde decorreu o estudo e aos professores e aos alunos envolvidos, bem como aos avaliadores que, com os seus pertinentes comentários, contribuíram significativamente para aumentar a qualidade do texto.

\section{REFERÊNCIAS}

ANTUNES, C.; BISPO, M.; GUINDEIRA, P. Novo descobrir a Terra. 8. ed. Porto: Areal Editores, 2010. AUSUBEL, D.; NOVAK, J.; HANESIAN, H. Psicologia Educacional. 2. ed. Rio de Janeiro: Interamerica, 1908.

BARRET, T.; MOORE, S. New approaches to problem-based learning: revitalizing your practice in higher education. Nova Iorque: Routledge, 2011.

BELEZA, M.; CAVALEIRO, M. FQ 7. Vila Nova de Gaia: Asa Editores, 2010.

BYBEE, R. A new challenge for education leaders: developing 21st-century workforce skills. In: RHOTON, J. (Ed). Science Education Leardship: best practices for the new century. USA: NTSA, 2010. p. 33-50.

CARVALHO, F.; SANTOS, A.; MELO, A.; NASCIMENTO, G.; COSTA, I. Conhecimentos prévios de estudantes do ensino fundamental, sobre conceitos básicos de ecologia. Revista da SBEnBio, São Paulo, n. 7, p. 1992-2003, out./2014.

CASTRO, D.; BEJARANO, N. O perfil de conhecimento sobre seres vivos pelos estudantes da 
coopec: uma ferramenta para planejar um ensino de ciências. Revista Ensaio, Belo Horizonte, v. 14, n. 3, p. 261-274, 2012.

ÇIMER, S.; ÇIMER, A.; URSAVAŞ, N. Student teachers' conceptions about global warming and changes in their conceptions during pre-service education. Educational Research and Reviews, Amesterdão, v. 6, n. 8, p. 592-597, 2011.

CHIN, C.; CHIA, L. Problem-Based Learning: Using students' questions to drive knowledge construction. Studies in Science Education, Abingdon, v. 44, n. 1, p. 1-39, 2004. Disponível em: <http://onlinelibrary.wiley.com/doi/10.1002/sce.10144/epdf>. Acesso em: 19 out. 2015.

COSTA, C. Interdisciplinaridade: das concepções às representações de práticas de professores de Ciências. In: CASTELlAR, S.; MUNHOZ, G. (Org.). Conhecimentos escolares e caminhos metodológicos. São Paulo: Xamã VM Editora e Gráfica Ltda, 2012. p. 101-120.

DAHLGREN, M.; CASTENSSON, R.; DAHLGREN, L. PBL from teachers' perspective. Higher Education, Dordrecht, v. 36, n. 4, p. 437-447, 1998. Disponível em: <http://link.springer.com/ article/10.1023\%2FA\%3A1003467910288\#page-1>. Acesso em: 16 out. 2015.

DEB. Orientações Curriculares para as Ciências Físicas e Naturais. Lisboa: ME, 2001.

DOVE, J. Student teachers' understanding of the greenhouse effect, ozone layer depletion, and acid rain. Environmental Educational Research, Abingdon, v. 2, p. 89-100, 1996.

DRIVER, R.; SQUIRES, A.; RUSHWORTH, P.; WOOD-ROBINSON, V. Making sense of secondary science. Londres: Routledge, 1994.

EUROPEAN COMISSION. Science education for Responsible Citizenship. Bruxelas: European Comission. 2015. Disponivel em: <http://ec.europa.eu/research/swafs/pdf/pub_science_ education/KI-NA-26-893-EN-N.pdf>. Acesso em: 10 dez. 2015.

FERREIRA, L. A aprendizagem do tema "Do Sol ao Aquecimento", no $10^{\circ}$ ano de escolaridade. 2014. 105p. Dissertação (Mestrado em Ciências da Educação, Área de Especialização em Supervisão Pedagógica na Educação em Ciências) - Instituto de Educação da Universidade do Minho, Braga, 2014. Disponível em: <http://repositorium.sdum.uminho.pt/handle/1822/36024>. Acesso em: 18 set. 2015. GANDRA, P. O efeito da aprendizagem da física baseada na resolução de problemas. 2001. 251p. (Mestrado em Ciências da Educação, Área de Especialização em Supervisão Pedagógica na Educação em Ciências) - Instituto de Educação da Universidade do Minho, Braga, 2001. (não publicada).

HANDE, S.; MOHAMMED, C.; KOMATTIL, R. Acquisition of knowledge, generic skills and attitudes through problem-based learning. Journal of Taibah University Medical Sciences, Amesterdão, v. 10, n. 1, p. 21-25, 2015. Disponível em: < http://www.sciencedirect.com/science/ article/pii/S1658361214000535>. Acesso em: 3 out. 2015.

HARTLEY, L.; MOMSEN, J.; MASKIEWICZ, A.; D’AVANZO, C. Energy and matter: differences in discourse in physical and biological sciences can be confusing for introductory biology students. BioScience, Oxford, v. 62, n. 5, p. 488-496, 2012. Disponível em: < http://bioscience.oxfordjournals. org/ content/62/5/ 488.short>. Acesso em: 5 out. 2015.

HATIRUSARU, V.; KUÇUKTURAN, A. Students' views on problem-based learning of $9^{\text {th }}$ grade industrial vocational high school. Procedia Social and Behavioral Sciences, Amesterdão, v. 1, p. 718-722, 2009. Disponível em: <http://www.scienc edirect.com/ science/article/pii/ S1877042809001281>. Acesso em: 4 out. 2015.

HMELO-SILVER, C. Problem-based learning: what and how do students learn?. Educational Psychology Review, Dordrecht, v. 16, n. 3, p. 235-266, 2004. Disponível em: < http://link.springer. com/article/10.1023\%2FB\%3AEDPR.00 00034022.16470.f3>. Acesso em: 16 out. 2014.

HODSON, D. Towards scientific literacy: a teachers' guide to the history, philosophy and sociology of science. Roterdão: Sense Publisher, 2008. 
HOOLBROK, J.; RANNIKMAE, M. The meaning of scientific literacy. Internacional Journal of Environmental \& Science Education, Den Haag, v. 4, n. 3, p. 275-288, 2009.

HUNG, W.; JONASSEN, D.; LIU, R. Problem-based learning. In: SPECTOR, J.; MERRILL, M.; MENRIERBOER, J.; DRISCALL, M. (Ed.). Handbook of research on educational communications and technology. Nova Iorque: LEA, 2008. p. 485-506.

JONASSEN, D. Learning to solve problems: an instructional design guide. São Francisco (USA): Pfeiffer, 2004.

KELES, S.; KEFELIB, P. Determination of student misconceptions in "photosynthesis and respiration" unit and correcting them with the help of cai material. Procedia Social and Behavioral Sciences, Amesterdão, v. 2, p. 3111-3118, 2010. doi:10.1016/j.sbspro.2010.03.474

KENNEDY, J.; LYONS, T.; QUINN, F. The continuing decline of science and mathematics enrolments in Australian high schools. Teaching Science, Deakin West, v. 60, n. 2, p. 34-46, 2014.

KÖSE, S. Diagnosing Student Misconceptions: Using Drawings as a Research Method. World Applied Sciences Journal, Deira, v. 3, n. 2, p. 283-293, 2008.

KURNAZ, M.; SAĞLAM-ARSLAN, A. A thematic review of some studies investigating students' alternative conceptions about energy. Eurasian Journal of Physics and Chemistry Education, Ankara, v. 3, n. 1, p. 51-74, 2011. Disponivel em: < http://www.eurasianjournals.com/index.php/ ejpce/article/view/642>. Acesso em: 15 dez. 2015.

LAMBROS, A. Problem-based learning in K-8 classrooms. Thousand Oaks: Corwin Press, 2002.

LEITE, L.; AFONSO, A. Aprendizagem baseada na Resolução de Problemas. Boletín das Ciências, Santiago de Compostela, n. 48, p. 253-260, 2001. Disponível em: <http://repositorium. sdum. uminho.pt/handle/1822/5538>. Acesso em: 19 set. 2015.

LEITE, L.; ESTEVES, E. Da integração dos alunos à diferenciação do ensino: o papel da aprendizagem baseada na resolução de problemas. In: CASTELLAR, S. (Org.). Conhecimentos escolares e caminhos metodológicos. São Paulo: EJR Xamã Editora, 2012. p. 137-152.

LEITE, L. et al. Ensino orientado para Aprendizagem Baseada na Resolução de Problemas: perspectivas de professores de Ciências e Geografia. Journal of Science Education, Bogota, v. 14, número especial, p. 28-32, 2013. Disponível em: <http://repositorium. sdum.uminho.pt/ handle/1822/24390>. Acesso em: 19 set. 2015.

MORGADO, S. Aprendizagem Baseada na Resolução de Problemas: um estudo centrado na formação contínua de professores de Ciências e de Geografia. 2013. 190p. Dissertação (Mestrado em Ciências da Educação, Área de Especialização em Supervisão Pedagógica na Educação em Ciências) - Instituto de Educação da Universidade do Minho, Braga, 2013. Disponível em: < http:/ / repositorium. sdum.uminho.pt/handle/1822/26740>. Acesso em: 18 set. 2015.

OCDE. What students know and can do: student performance in mathematics, reading and science, summarises the performance of students in PISA 2012. Bruxelas: OECD Publishing, 2014. Disponível em: <http://dx.doi.org/10.1787/9789264201118-en>. Acesso em: 10 out. 2015.

PEDERSON, S.; LIU, M. Teachers' beliefs about issues in the implementation of a student centered learning environment. ETR\&D, Dordrecht, v. 51, n. 2, p. 57-76, 2003. Disponível em: < http:/ /www. columbia.edu/ lsb31/Student_centered.pdf >. Acesso em: 16 out. 2015.

PEPPER, C. Implementing problem-based learning in a science faculty. Issues in Educational Research, Como DA, v. 18, n. 1, p. 60-72, 2008. Disponível em: <http://www. iier.org.au/iier18/ pepper.pdf>. Acesso em: 15 set. 2015.

POTVIN, P.; HANS, A. Analysis of the decline in interest towards school science and technology from grades 5 through 11. Journal of Science Education and Technology, Dordrecht, v. 23, n. 6, p. 784-802, 2014. PRINCE, M. Does Active Learning work? A review of the research. Journal of Engineering 
Education, Malden, v. 93, n. 3, p. 223-231, 2004.

RAINE, D.; SYMONS, S. Problem-based learning: undergraduate physics by research. Contemporary Physics, Abindgon, v. 53, n. 1, p. 39-51, 2012. Disponível em: < http://www.tandfonline.com/doi/ab s/10.1080/00107514.2011.615162>. Acesso em: 15 set. 2015.

RIBEIRO, L.; MIZUKAMI, M. An experiment with PBL in higher education as appraised by the teacher and students. Interface - Comunic, Saúde, Educ, Botucatu, v. 9, n. 17, p. 357-368, 2005. Disponível em: <http://www.scielo.br/scielo.php?pid =S141432832005000200011\&script=sci_ arttext>. Acesso em: 15 set. 2015.

RUIZ-GALLARDO, J-R.; CASTAÑO, S.; GÓMEZ-ALDAY, J.; VALDÉS, A. Assessing student workload in problem based learning. Teaching and Teacher Education, Amesterdão, v. 27, p. 619627, 2011. Disponível em: <http://www.sc iencedirect.com/ science/article/pii/S0742051X100019 15>. Acesso em: 10 out. 2015.

SAHIN, M. Exploring University students' expectations and beliefs about physics and physics learning in a problem-based learning context. Eurasia Journal of Mathematics, Science \& Technology Education, Ankara, v. 5, n. 3, p. 321-333, 2009. Disponível em: <http://www.ejmste.com/v5n4/ eurasia_v5n4_sahin.pdf>. Acesso em: 05 out. 2015.

ŞAHIN, M.; YOREK, N. A comparison of problem-based learning and traditional lecture students' expectations and course grades in an introductory physics classroom. Scientific Research and Essay, Èbene, v. 4, n. 8, p. 753-762, 2009. Disponível em: <http://www.academicjournals.org/app/ webroot/article/article1380629179_Sahin\%20and\%20Yorek.pdf>. Acesso em: 5 dez. 2015.

SELÇUK, G. The effects of problem-based learning on pre-service teachers' achievement, approaches and attitudes towards learning physics. International Journal of the Physics Sciences, Èbene, v. 5, n. 6, p. 711-723, 2010. Disponível em: <http://boltz.ccne.ufsm.br/pub/mpeac/other/ selcuk_ijps_vol5_2010.pdf>. Acesso em: 27 set. 2015.

SELÇUK, G.; CALIŞKAN, S.; ŞAHIN, M. A comparison of achievement in problem-based learning, strategic and traditional learning classes in physics. International Journal on New Trends in Education and Their Implications, Ankara, v. 4, n. 4, article 14, 2013. Disponível em: <http:/ /www. ijonte.org/FileUpload/ks63207/File/14. selcuk.pdf>. Acesso em: 27 set. 2015.

SJØBERG, S.; SCHREINER, C. The ROSE project: an overview and key findings. 2010. Disponivel em: < http://roseproject.no/network/countries/norway/eng/nor-Sjoberg-Schreineroverview-2010.pdf.> Acesso em: 1 dez. 2015.

SULAIMAN, F. Students' perceptions of implementing problem-based learning in a physics course. Procedia Social and Behavioral Sciences, Amesterdão, v. 7, p. 355-362, 2010. Disponível em: < http:// www.sciencedirect.com/science/article/pii/S1877 042810020 525>. Acesso em: 27 set. 2015.

VASCONCELOS, C.; TORRES, J. A Aprendizagem Baseada na Resolução de Problemas na Educação Ambiental. In: Encontro Sobre Educação em Ciências através da ABRP, Braga, 2013. LEITE, L. et al. (Org.). Actas do Encontro Sobre Educação em Ciências através da Aprendizagem Baseada na Resolução de Problemas (p. 48-62). Braga: Universidade do Minho, 2013. (CD-ROM). VIEIRA, P. Aprendizagem baseada na resolução de problemas e webquests: um estudo com alunos do $8^{\circ}$ ano de escolaridade, na temática "fontes de energia". 2007. 205p. Dissertação (Mestrado em Ciências da Educação, Área de Especialização em Supervisão Pedagógica em Ensino das Ciências) - Instituto de Educação da Universidade do Minho, Braga, 2007. Disponível em: < http:// repositorium.sdu m.uminho.pt/handle/1822/7913>. Acesso em: 18 set. 2015.

WOODS, D. Problem-based learning: How to gain the most from PBL. Hamilton: McMaster University, 2000.

ZOMPERO, A. Concepções de alunos do ensino fundamental sobre microrganismos em aspectos que envolvem saúde: implicações para o ensino aprendizagem. Experiências em Ensino de Ciências, 
Cuiabá, v. 4, n. 3, p. 31-42, 2009.

ZOMPERO, A.; LABURU, C. A decomposição da matéria orgânica nas concepções de alunos do ensino fundamental: aspectos relativos à educação ambiental. Experiências em Ensino de Ciências, Cuiabá, v. 5, n. 1, p. 67-75, 2010.

Data de recebimento: 11/01/2016

Data de aprovação: 17/06/2016

Data da versão final: 11/07/2016

Contato:

Sofia Morgado

Instituto de Educação (IE)

Universidade do Minho

Campus de Gualtar

4710-057 Braga - Portugal

E-mail: sofiamorgado@ie.uminho.pt

\section{ERRATA}

No do artigo Ensino orientado para a aprendizagem baseada na resolução de problemas e ensino tradicional: um estudo centrado em "transformação de matéria e de energia", com número de DOI: http://dx.doi. org/10.1590/1983-21172016180204, publicado em Ahead of print, referente ao periódico Revista Ensaio Pesquisa em Educação em Ciências, vol.18 n ${ }^{\circ} .2$, Belo Horizonte, mai./ago. 2016: <http://www.scielo.br/scielo.php?script=sci_ arttext\&pid=S1983-21172016005003101\&lng=pt\&nrm=iso\&tlng=pt $>$, na página 1, na Sessão Titulação “Célia Fernandes****:” linha 24,

onde se lia:

****Universidade do Porto (UP) Porto - Portugal.

leia-se:

****Escola Secundária Castêlo da Maia, Maia - Portugal

No do artigo Ensino orientado para a aprendizagem baseada na resolução de problemas e ensino tradicional: um estudo centrado em "transformação de matéria e de energia", com número de DOI: http://dx.doi. org/10.1590/1983-21172016180204, publicado em Ahead of print, referente ao periódico Revista Ensaio Pesquisa em Educação em Ciências, vol.18 n ${ }^{\circ} .2$, Belo Horizonte, mai./ago. 2016: <http://www.scielo.br/scielo.php?script=sci_ arttext\&pid=S1983-21172016005003101\&lng=pt\&nrm=iso\&tlng=pt $>$, na página 1, na Sessão Titulação “Eleutério Silva*****” linha 31,

onde se lia:

****Universidade do Porto (UP) Porto - Portugal.

leia-se:

****Escola Secundária Castêlo da Maia, Maia - Portugal 
No do artigo Ensino orientado para a aprendizagem baseada na resolução de problemas e ensino tradicional: um estudo centrado em “transformação de matéria e de energia”, com número de DOI: http://dx.doi. org/10.1590/1983-21172016180204, publicado em Abead of print, referente ao periódico Revista Ensaio Pesquisa em Educação em Ciências, vol.18 n ${ }^{\circ} .2$, Belo Horizonte, mai./ago. 2016: <http://www.scielo.br/scielo.php?script $=$ sci_ arttext\&pid $=$ S1983-21172016005003101\&lng $=$ pt\&nrm $=$ iso\&tlng $=$ pt $>$, na página 25, sessão Contato,

onde se lia:

Contato:

Sofia Morgado

Instituto de Educação (IE)

Universidade do Minho

Campus de Gualtar

Braga - Portugal

4710-057

sofiamorgado@ie.uminho.pt

leia-se:

Contato:

Sofia Morgado

Instituto de Educação (IE)

Universidade do Minho

Campus de Gualtar

4710-057 Braga - Portugal

E-mail: sofiamorgado@ie.uminho.pt

Laurinda Leite

Universidade do Minho

Instituto de Educação

Campus de Gualtar

4710-057 BRAGA - Portugal

E-mail: Ileite@ie.uminho.pt

Luís Dourado

Universidade do Minho

Instituto de Educação

Campus de Gualtar

4710-057 BRAGA - Portugal

E-mail: Idourado@ie.uminho.pt

Célia Silva

Escola Secundária do Castêlo da Maia Rua Professora Idalina Santos Quelhas 4475-640 Maia - Portugal

E-mail: celiafernandes.escm@gmail.com

\section{Eleutério Silva}

Escola Secundária do Castêlo da Maia Rua Professora Idalina Santos Quelhas 4475-640 Maia - Portugal

E-mail: eleuterioacursiosilva@gmail.com 